\title{
Modeling and Trend Analysis of Climatic Variables of Ranchi District, Jharkhand
}

\author{
PAWAN JEET ${ }^{1 *}$, K N SINGH ${ }^{2}$, RAJEEV RANJAN KUMAR ${ }^{2}$, BISHAL GURUNG ${ }^{2}$, A K SINGH ${ }^{1}$ AND A UPADHYAYA ${ }^{1}$
}

\begin{abstract}
In this paper, an attempt has been made to study the temporal variation in monthly, seasonal and annual rainfall, and average annual maximum and minimum temperature for the period 1901-2015 over Ranchi district of Jharkhand, India. Long-term changes in rainfall, temperature was determined by Man-Kendall rank statistics and Sen's slope, and forecasting of time series was determined by ARIMA model. The results revealed that there was significant decrease of average rainfall in the month of February and August while increase in month May and Premonsoon season. Average rainfall in the month of February, May, August and Pre-monsoon season showing insignificant increasing as well as decreasing rainfall trend. The average annual maximum and minimum temperature showing decreasing and increasing trend over Ranchi district during the period 1901 to 2015. This paper also describes five-year prediction of rainfall and temperature climatic variables.
\end{abstract}

KEYWORDS

Mann Kendall, Sen's slope, ARIMA, forecasting and trend analysis

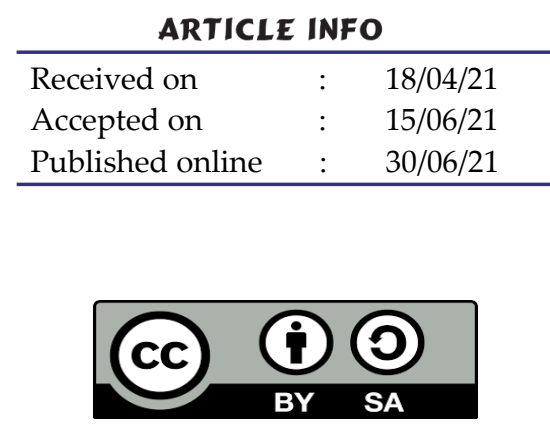

\section{INTRODUCTION}

$\mathrm{W}$ ater is the major renewable resource has become a prime concern for development and planning including food production, biodiversity management, flood control and effective water resource management. According to the Intergovernmental Panel on Climate Change (IPCC, 2007) global surface warming is occurring at a rate of $0.74 \pm 0.18{ }^{\circ} \mathrm{C}$ during the period 1906-2005. It has also been reported that decrease in annual average runoff and availability of water will project up to $10-30 \%$ mainly due to change in rainfall and temperature pattern. Rainfall and temperature trend analysis on different spatial and temporal scales has been become a great concern during the past century because of the global climate change from the scientific community. Zhang et al (2000) indicates a small positive global trend, even though large areas are characterized by negative trends. The Indian sub-continent will adversely be affected by enhanced extremities of climate, substantial reduction of summer rainfall and rising temperature in some parts and water stress by 2020 (Ma and Malini, 2003).

Study of different time series data have proved that trend is either decreasing or increasing, both in case of temperature and rainfall. Trend and magnitude of warming of India during the last century is matching with the global condition. Climate change over India by southwest monsoon causes drastic change in hydrological parameters such as rainfall, evaporation and stream flow etc., would have a significant impact of agricultural production, water resources management and overall economic growth of the country (Abeysingha et al 2014 and Bera 2017). Therefore, trend analysis using statis- tical tools for long-term climatic data (i.e. rainfall and temperature) has been extensively useful in study and proper assessment of impacts of climatic change along with its variability (Duhan and Pandey 2013; Jain et al, 2013 and Jeet et al 2017). Nonparametric method of Sen's slope estimator has been frequently used to estimate the trend's magnitude, whose statistical significance was assessed by the MannKendall test (Pohlert, 2016). In general, trend estimation studies for different climatic variables is determined either using parametric test or nonparametric methods ((Kumar et al, 2016) . Previous studies have detected the significant decreasing trends of rainfall in the monsoon season, whereas during December month, significant increasing trend of rainfall have been observed in Jharkhand state ((Kumari et al, 2014).

A time series data must exhibit smooth behavior by avoiding inconsistent result. The most common time series model is the autoregressive integrated moving average (ARIMA) model is widely used in forecasting hydrologic and climatic time series modeling. In this model variable is forecasted by a linear combination of the previous state of variable (pure AR component), and previous forecast error (pure MA component). This model was developed for a climatic time-series forecasting model to forecast climatic variations and ARIMA model have been applied, and improved by many hydrologists for forecasting long as well as short term climate time series data ((Sultana and Hasan, 2015) and also applied in forecasting of crop production ((Kumar and Anand, 2014). The study of long term time series is critically important for food security and economy dependency on rainfall and temperature climatic parameters of Ranchi district of Jharkhand. Attempts

\footnotetext{
${ }^{1}$ Division of Land \& Water Management, ICAR Research complex for Eastern Region, Patna-800014, Bihar, India

2 ICAR - Indian Agricultural Statistics Research Institute, New Delhi110012, India

*Corresponding author email: pawan.btag@gmail.com
} 
have been made in the past to determine trends in the rainfall and temperature at national and regional scales ((Mali et al, 2017).

In the present study, a much detailed view has been taken to assess the presence of linear monotonic upward or downward trends in the temporal structure of rainfall and temperature and to quantify the trend statistics on monthly, seasonal and annual scales for Ranchi districts of Jharkhand covering all agro-climatic regions.

\section{MATERIALS AND METHODS}

\section{Study Area}

Ranchi district (Jharkhand) is situated at an altitude of $653 \mathrm{~m}$ above mean sea level and is its extension is $23^{\circ} 21^{\prime} 0^{\prime \prime} \mathrm{N}$ latitude and $85^{\circ} 13^{\prime} 48^{\prime \prime}$ E longitude (Figure 1 ). It has an area of $5231 \mathrm{sq}$. $\mathrm{km}$ and population of $29,12,022$ persons. The soil of the district is of lateritic and loam soil type. The majority of the soil in the area is acidic. This district receives an average annual rainfall of $1530 \mathrm{~mm}$, out of which about 80 per cent rainfall was during the monsoon season. The temperature in winter season ranges from a minimum $5.3{ }^{\circ} \mathrm{C}$ to maximum $20.9{ }^{\circ} \mathrm{C}$ and in summer season ranges from minimum $20.6{ }^{0} \mathrm{C}$ to maximum $41{ }^{0} \mathrm{C}$. The forest cover is $20.99 \%$ of total area of the district. District has a moderate climate due to hilly region and dense deciduous forest coverage. Rice, Millets, Pulses and oil seeds is the major agricultural crops. The total cultivable area of the district is $6.1 \times 10^{5}$ ha, out of which $33 \%$ of the total cultivable areas is net sown area. Current fallow, other fallow and cultivable wasteland is $1.01 \times 10^{5}$ ha. Subarnarekha, South Koel and Sankh rivers is an important river, which runoff the excess water during the monsoon season. Only about 8 percent of cultivable land area has irrigation facility and well and canals is the major source of irrigations. Geologically, the area is comprised with Archean granites, gneisses and schists rocks type. The district have a good source of lime stone, coal, asbestos and ornamental stones etc. which provide a livelihood income source of population. The district comprises three subdivisions (i.e. Ranchi Sadar, Bundu and Khunti) and twenty development blocks.

\section{Data used}

To study the temporal distribution in climate of the Ranchi district, a trend analysis of the annual, seasonal and monthly rainfall $(\mathrm{mm})$, and annual minimum and maximum temperature $\left({ }^{0} \mathrm{C}\right)$ were considered. The monthly rainfall and annual temperature data over 115 years (1901- 2015) from two stations was obtained from India water portal (www.indiawater portal.org) to examine the spatial and temporal variability of the rainfall and temperature data. Trend analysis of rainfall was performed for Ranchi districts of Jharkhand on annual, seasonal (pre-monsoon from March to May, monsoon from June to September, post-monsoon from October to November, and winter from December to February) and monthly basis, and trend analysis of temperature (maximum and minimum) was performed on annual basis.

Descriptive Statistics
The preliminary analysis of statistical parameters(minimum value, maximum value, mean, $1^{\text {st }}$ quantile, median, $3^{\text {rd }}$ quantile, standard deviation (SD), Variance, Coefficient of variance (CV), Skewness and kurtosis) of the monthly, seasonal and annual rainfall and annual temperature (1901-2015) of Ranchi district of Jharkhand was calculated by using $\mathrm{R}$ programming language.

\section{ARIMA model}

Autoregressive integrated moving average (ARIMA) is a method and tool for displaying and analysing univariate time series forecasts. This model is used to make forecasting, to find the best fit of a time series to past values of this time series (Li, 2009). A generalization of ARMA models which incorporates a non-stationary time-series is obtained by introducing the differencing into the model. This model is an important part of the Box-Jenkins approach to time-series modeling. A process $\left\{x_{t}\right\}$ is said to follow an ARIMA model, denoted by ARIMA $(\mathrm{p}, \mathrm{d}, \mathrm{q})$, if $\nabla^{d} x_{t}=(1-B)^{d} x_{t}$ is ARMA $(p, q)$. The model is written in the form

$$
\phi(B)(1-B)^{d} x_{t}=\theta(B) \omega_{t}\left\{\omega_{t}\right\}-W N\left(0, \sigma^{2}\right)
$$

where, WN indicating White Noise. The integration parameter $d$ is a nonnegative integer. When $d=0, \operatorname{ARIMA}(p, d, q)$ $\equiv$ ARMA (p, q). This model is used for forecasting next five year time series by using forecast package in $\mathrm{R}$ language.

\section{Mann-Kendall (MK) Test}

The non-parametric Mann-Kendall test is generally used to detect monotonic upward or downward trends in climatologic and hydrologic time series. This test is applied to assess the significance of the trend of the blended time series ((Zhang et al, 2000). This is found to be an excellent tool for trend detection by many researchers in similar application. The MannKendall test statistic is as follows

$S=\sum_{k=1}^{n-1} \sum_{j=k+1}^{n} \operatorname{sgn}\left(X_{J}-X_{K}\right)=\sum_{k=1}^{n-1} \sum_{j=k+1}^{n} \operatorname{sgn}(x)$

where

$$
\operatorname{sgn}(x)=\left\{\begin{array}{cc}
1 & \text { if } x>0 \\
0 & \text { if } x=0 \\
-1 & \text { if } x>0
\end{array}\right\}
$$

It has been documented that when $\mathrm{n}>10$, the mean of Sis $\mathrm{E}(\mathrm{s})$ $=0$ and the variance $\left(\sigma^{2}\right)$ of $S$ is

$$
\sigma^{2}=\frac{\left\{n(n-1)(2 n+5)-\sum_{j=1}^{p} t_{j}\left(t_{j}-1\right)\left(2 t_{j}+5\right)\right\}}{18}
$$

Where, $\mathrm{n}$ is the number of time series data points, $\mathrm{p}$ is the number of the tied groups in the time series data set and $t_{j}$ is the number of data points in the jth tied group. A positive value of $S$ indicates an increasing trend, and negative value indicates a decreasing trend of time series data set.

The test statistic $S$ is closely related to Kendall's rank correlation coefficient, tau $(\tau)$ as given by

$$
\tau=\frac{S}{D}
$$




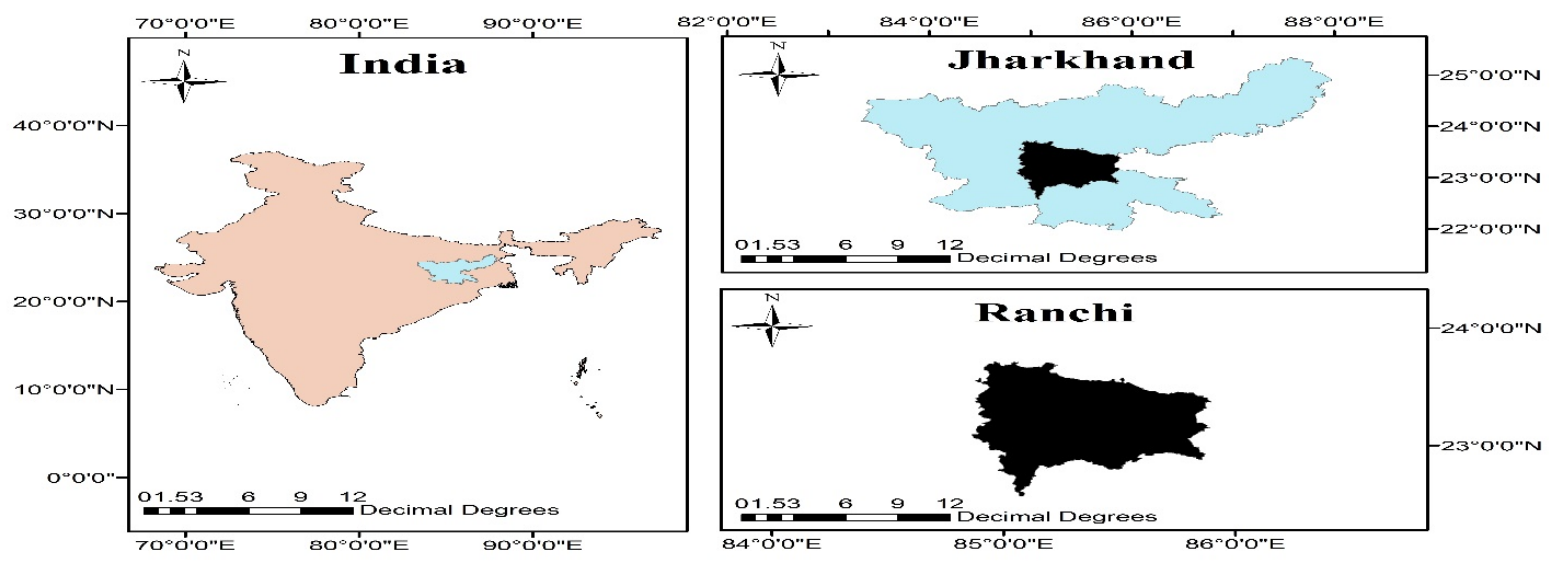

Fig. 1: Location map of Ranchi district, Jharkhand

Where, $\mathrm{S}$ is the Kendall score and D is the maximum possible value of $S$. and

$D=\left[\frac{1}{2} n(n-1)-\frac{1}{2} \sum_{j=1}^{p} t_{j}\left(t_{j}-1\right)\right]^{\frac{1}{2} \times\left[\frac{1}{2} n(n-1)\right]^{\frac{1}{2}}}$

The Z-statistics is follows as

$$
Z=\left\{\begin{array}{cc}
\frac{S-1}{\sqrt{\operatorname{Var}(S)}} & \text { if } S>0 \\
0 & \text { if } S=0 \\
\frac{S+1}{\sqrt{\operatorname{Var}(S)}} & \text { if } S<0
\end{array}\right\}
$$

The null hypothesis, $\mathrm{H}_{0}$, is that the data are independent and are normally distributed. The alternative hypothesis, $\mathrm{H}_{A}$, data follows a monotonic decreasing or increasing trend.

\section{Theil-Sen's estimator method}

This method is generally used to compute magnitudes of trend of time series data. It computes both the intercept and slope of trend of time series data. A set of linear slopes is given by following relations:

$$
\beta=\operatorname{median}\left(\frac{X_{j}-X_{i}}{j-1}\right) \text { for }(1 \leq i<j \leq n)
$$

where $\beta$ is the slope of time series data plots, $X$ denotes the variable, $n$ is the number of data points, and $i, j$ are indices. A positive value of $\beta$ indicates an upward trend and the negative value of $\beta$ indicates a downward trend in the time series.

\section{RESULTS AND DISCUSSIONS}

Statistical Characteristics of Rainfall (Monthly, Seasonal and Annual) and A nnual Temperature

Basic statistical parameters, such as minimum value, maximum value, mean, $1^{\text {st }}$ quantile, median, $3^{\text {rd }}$ quantile, standard deviation (SD), variance (Var), coefficient of variance (CV), coefficient of skewness (CS) and coefficient of kurtosis (CK) of monthly, seasonal (monsoon, post-monsoon, summer and winter) and annual rainfall (1901-2015) and temperature (1901-2015) were analyzed and presented in Table 1 . The rainfall and temperature series for the period 1901-2015 (115 years) was tested for homogeneity, and the results showed that the rainfall and temperature time series to be symmetrically distributed for the month July, August and September, and seasonally symmetrically distributed for winter, post monsoon and SW monsoon. The rainfall and temperature of Ranchi district is symmetrically distributed throughout year. Trend analysis

To study the temporal changes in climate of the Ranchi district, Jharkhand trend analysis of monthly, seasonal and annual rainfall, and annual maximum and minimum temperature climate variables were assumed. Trend analysis was carried out at 5\% level of significance. The value of Sen's slope and Mann-Kendall test for rainfall and temperature time series data of Ranchi district of Jharkhand estimated for monthly, seasonal and annual trend analysis and presented in Table 2. Only rainfall for month February ( $\mathrm{S}=-$ 928 and $p=0.025)$ as well as August $(S=-971$ and $p=0.019)$ show a significant $(\mathrm{p}<0.05)$ negative trend and rainfall for month May ( $\mathrm{S}=973$ and $\mathrm{p}=0.018$ ) and for Pre-monsoon season $(S=815$ and $p=0.049)$ show a significant $(\mathrm{p}<0.05)$ positive trend. Otherwise, except month February, May, August and pre-monsoon season showing insignificant negative as well as positive trend. The average annual maximum temperature and minimum temperature also showing decreasing and increasing trend respectively. The trend analysis of seasonal and annual average rainfall for period 1901 to 2015 was depicted in Figure 2. The pre-monsoon and post-monsoon average rainfall time series (1901-2015) indicates increasing trend and winter season average rainfall time series indicates decreasing trend. The average annual rainfall time series of Ranchi district of Jharkhand indicates the decreasing trend. The increasing or decreasing trend of climatic variables would be helpful in the forecasting of climate variables in future and also helpful in district management planning. 
Table 1: Descriptive statistics of rainfall and temperature

\begin{tabular}{|c|c|c|c|c|c|c|c|c|c|c|c|c|c|c|c|}
\hline \multicolumn{16}{|c|}{ Rainfall } \\
\hline \multicolumn{3}{|c|}{ Parameteirs. } & Max. & Mean & & $\begin{array}{l}1^{s t} \\
\mathrm{Qu} .\end{array}$ & Media & $\begin{array}{r}\mathrm{anB}^{r d} \\
\mathrm{Qu}\end{array}$ & Var. & SD & & CV $(\%)$ & CS & & CK \\
\hline \multicolumn{3}{|c|}{ Annua 791.80} & 2017.20 & 1312.80 & & 1176 & 1296.2 & 201422 & 46675 & 9216.05 & & 16.46 & .37 & & .42 \\
\hline \multicolumn{3}{|c|}{ Winter0.97 } & 151.83 & 50.31 & & 21.17 & 42.18 & 75.14 & 1131.9 & 9433.64 & & 66.88 & .67 & & -.17 \\
\hline \multicolumn{16}{|c|}{$\begin{array}{l}\text { Mon- } \\
\text { soon }\end{array}$} \\
\hline \multicolumn{16}{|c|}{$\begin{array}{l}\text { Mon- } \\
\text { soon }\end{array}$} \\
\hline \multicolumn{16}{|c|}{$\begin{array}{l}\text { Mon- } \\
\text { soon }\end{array}$} \\
\hline Jan & 0.19 & & 73.35 & 16.84 & & 2.97 & 10.99 & 28.13 & 294.55 & 517.16 & & 101.93 & 1.15 & & .68 \\
\hline Feb & 0.28 & & 127.71 & 33.47 & & 10.83 & 22.86 & 50.07 & 916.35 & 530.27 & & 90.45 & 1.16 & & .57 \\
\hline Mar & .20 & & 129.11 & 24.10 & & 4.17 & 15.36 & 37.83 & 626.85 & 525.04 & & 103.89 & 1.49 & & 2.47 \\
\hline Apr & .23 & & 84.55 & 22.27 & & 6.89 & 16.36 & 29.98 & 397.89 & 919.95 & & 89.58 & 1.19 & & .68 \\
\hline May & 1.37 & & 168.35 & 40.89 & & 17.49 & 30.85 & 52.93 & 1208.6 & 6934.77 & & 85.03 & 1.53 & & 2.45 \\
\hline Jun & 35.29 & & 525.36 & 190.63 & & 115.96 & 172.19 & 249.83 & 9979.1 & 1299.90 & & 52.40 & .93 & & .67 \\
\hline Jul & 77.62 & & 639.03 & 325.80 & & 263.98 & 317.56 & 388.12 & 9731.9 & 9898.65 & & 30.28 & .22 & & .38 \\
\hline Aug & 157.70 & & 615.20 & 361.80 & & 281.40 & 358.40 & 432.40 & 10243 & 1901.21 & & 101.21 & .28 & & -.61 \\
\hline Sep & 76.50 & & 413.92 & 212.01 & & 157.61 & 209.58 & 258.62 & 5326.1 & 1172.98 & & 34.42 & .63 & & .14 \\
\hline Oct & 2.40 & & 281.02 & 73.89 & & 31.67 & 61.11 & 99.22 & 3000.1 & 1354.77 & & 74.13 & 1.12 & & 1.26 \\
\hline Nov & 0 & & 44.11 & 7.44 & & 0.28 & 3.42 & 10.64 & 90.95 & 9.54 & & 128.13 & 1.57 & & 1.94 \\
\hline Dec & 0 & & 29.51 & 3.70 & & 0 & .70 & 5.82 & 35.66 & 5.97 & & 161.52 & 2.11 & & 4.46 \\
\hline \multicolumn{16}{|c|}{ Temperature } \\
\hline Max. & & 28.96 & 31.74 & & 30.13 & 29.45 & 30.25 & 30.57 & .48 & .70 & 2.31 & -.02 & & -.79 & \\
\hline Min. & & 17.67 & 20.27 & & 19.04 & 18.52 & 18.80 & 19.95 & .56 & .75 & 3.93 & .30 & & -1.20 & \\
\hline
\end{tabular}

\section{Prediction and Forecasting}

ARIMA model was used for forecasting next five-year time series data for monthly, seasonal and annual rainfall, average annual maximum and minimum temperature. ARIMA mod- els are fitted on these data series for the period 1901-2015 and forecasted from 2016 to 2020 . The maximum likelihood estimates, AIC and BIC of the model are presented in Table 3 and Table 4.
The results indicate that, the rainfall for month Feb, May, July, August and winter season fitted for $\operatorname{ARIMA}(3,1,3), \operatorname{ARIMA}(0,11), \operatorname{ARIMA}(1,0,0), \operatorname{ARIMA}(0,1,1)$ and ARIMA $(1,0,0)$ respectively and this month and season are able to forecast future times series of rainfall based on previous time series data (Table 3 ). Otherwise, except above month, season and annual time series are fitted with $\operatorname{ARIMA}(0,0,0)$ are able to forecast future rainfall based on average of previous time series data (Table 4 ). For the minimum and maximum temperature, the best fitted models are $\operatorname{ARIMA}(0,1,2)$ and $\operatorname{ARIMA}(2,1,2)$ respectively (Table 3 ). 
Table 2: Value of Sen's Slope and Mann-Kendall test of monthly, seasonal, annual rainfall and annual temperature (1901-2015)

\begin{tabular}{|c|c|c|c|c|c|c|}
\hline \multicolumn{7}{|l|}{ Rainfall } \\
\hline Parameters & $S$ & Tau & $\operatorname{Var}(S)$ & p-value & Sen slope & Intercept \\
\hline Jan & 678 & 0.104 & 171092 & 0.101 & 0.042 & -72.243 \\
\hline Feb & -928 & -0.142 & 171157.3 & 0.025 & -0.137 & 291.851 \\
\hline Mar & -91 & -0.014 & 171093 & 0.827 & -0.007 & 30.751 \\
\hline Apr & 534 & 0.082 & 171154.7 & 0.197 & 0.057 & -96.852 \\
\hline May & 973 & 0.148 & 171158.3 & 0.018 & 0.175 & -310.513 \\
\hline Jun & 339 & 0.052 & 171158.3 & 0.413 & 0.259 & -341.103 \\
\hline Jul & 165 & 0.025 & 171158.3 & 0.691 & 0.131 & 62.456 \\
\hline Aug & -971 & -0.148 & 171158.3 & 0.019 & -0.697 & 1730.028 \\
\hline Sep & 21 & 0.003 & 171158.3 & 0.961 & 0.007 & 194.208 \\
\hline Oct & 195 & 0.030 & 171158.3 & 0.639 & 0.066 & -67.097 \\
\hline Nov & -27 & -0.004 & 170658.3 & 0.949 & 0.000 & 3.419 \\
\hline Dec & 25 & 0.004 & 162634.3 & 0.952 & 0.000 & 0.699 \\
\hline Winter & -555 & -0.085 & 171158.3 & 0.180 & -0.131 & 301.100 \\
\hline Pre Monsoon & 815 & 0.124 & 171158.3 & 0.049 & 0.255 & -422.266 \\
\hline SW Monsoon & -281 & -0.043 & 171158.3 & 0.498 & -0.382 & 1838.332 \\
\hline Post Monsoon & 221 & 0.034 & 171158.3 & 0.594 & 0.066 & -53.949 \\
\hline Annual & -169 & -0.026 & 171158.3 & 0.684 & -0.239 & 1768.896 \\
\hline \multicolumn{7}{|c|}{ Average Temperature } \\
\hline Maximum & -2343 & -0.352 & 175623 & $<0.001$ & -0.012 & 53.980 \\
\hline Minimum & 3039 & 0.457 & 175604.3 & $<0.001$ & 0.015 & -11.615 \\
\hline
\end{tabular}

Table 3: Log likelihood,AIC and BIC values of fitted ARIMA models

\begin{tabular}{|c|c|c|c|c|c|c|c|c|c|c|c|c|}
\hline \multicolumn{13}{|l|}{ Rainfall } \\
\hline Parameters & ARIMA Model & AR1 & AR2 & AR3 & MA1 & MA2 & MA3 & $\sigma^{2}$ & Log liklihood & AIC & $\mathrm{BIC}$ & $\mathrm{AICc}$ \\
\hline Feb & $(3,1,3)$ & 1.1506 & -0.54 & -0.23 & -2.31 & 2.06 & -0.71 & 853.7 & -545.17 & 1104.3 & 1123.5 & 1105.4 \\
\hline May & $(0,1,1)$ & & & & -0.92 & & & 1189 & -565.86 & 1135.7 & 1141.2 & 1135.8 \\
\hline Jul & $(1,0,0)$ & 0.1641 & & & & & & 9563 & -689.21 & 1384.4 & 1392.7 & 1384.6 \\
\hline Aug & $(0,1,1)$ & & & & -0.91 & & & 10079 & -687.61 & 1379.2 & 1384.7 & 1379.3 \\
\hline Winter & $(1,0,0)$ & -0.181 & & & & & & 1106 & -565.16 & 1136.3 & 1144.6 & 1136.5 \\
\hline \multicolumn{13}{|l|}{ Temperature } \\
\hline Max. & $(2,1,2)$ & 0.9307 & -0.31 & & -1.66 & 0.794 & & 0.168 & -59.34 & 128.67 & 142.4 & 129.22 \\
\hline Min. & $(0,1,2)$ & & & & -0.25 & -0.33 & & 0.123 & -42.05 & 90.11 & 98.34 & 90.33 \\
\hline
\end{tabular}



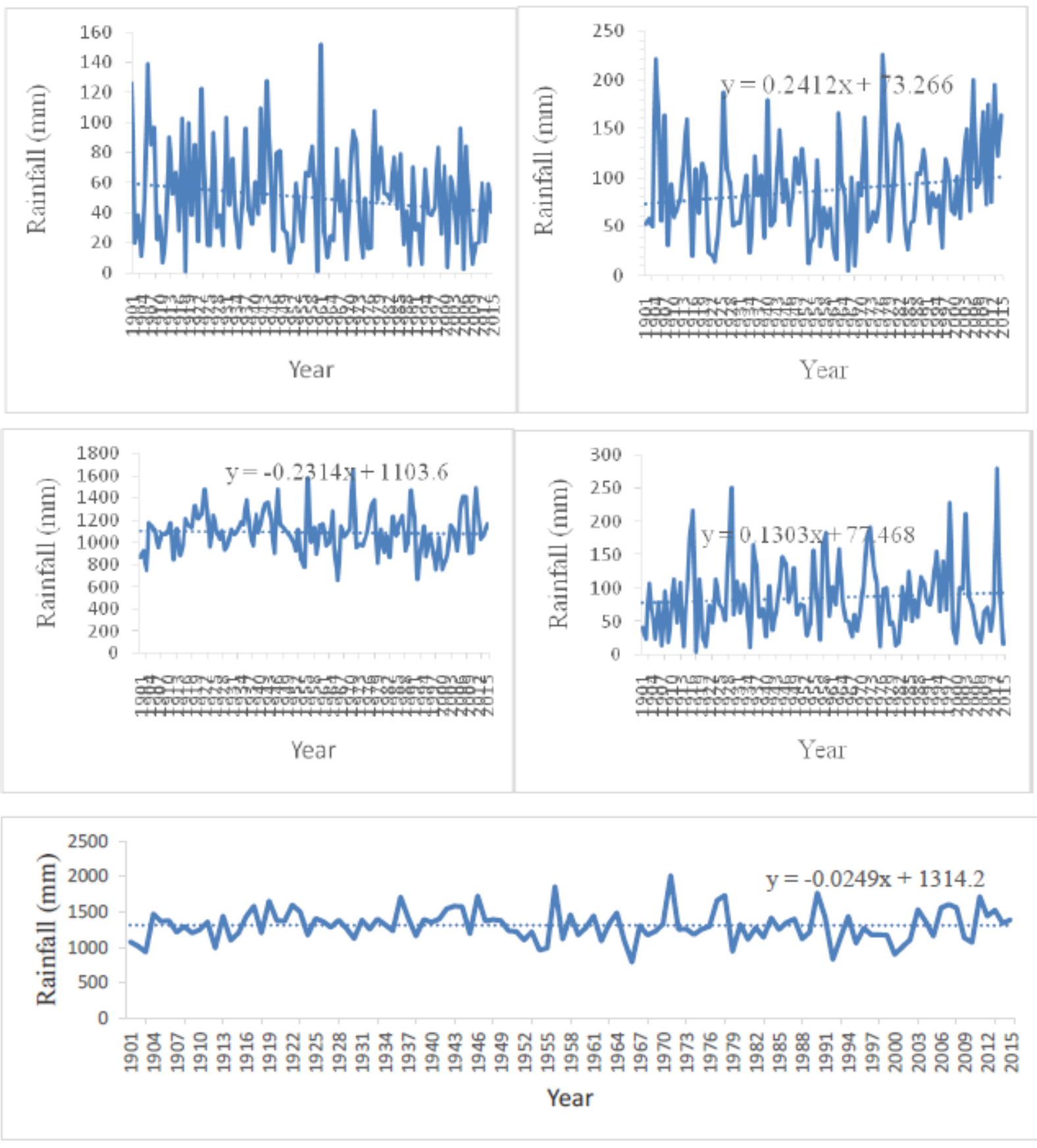

Fig. 2: Temporal variation of seasonal rainfall trend (a) Winter(b) Pre-monsoon (c) SW Monsoon (d) Post monsoon and (e) Annual Rainfall ofRanchi district, Jharkhand (1901-2015) 
Table 4: Log likelihood, AIC and BIC values of fitted ARIMA model $(0,0,0)$

\begin{tabular}{lllllll}
\hline Parameters & ARIMA Model & $\sigma^{2}$ & Log liklihood & AIC & BIC & AICc \\
Jan & $(0,0,0)$ & 294.6 & -489.59 & 983.18 & 988.67 & 983.29 \\
Mar & $(0,0,0)$ & 626.8 & -533.02 & 1070.03 & 1075.5 & 1070.14 \\
Apr & $(0,0,0)$ & 397.9 & 506.88 & 1017.76 & 1023.3 & 1017.87 \\
Jun & $(0,0,0)$ & 9979 & -692.15 & 1388.3 & 1393.8 & 1388.41 \\
Sep & $(0,0,0)$ & 5326 & -656.05 & 1316.09 & 1321.6 & 1316.2 \\
Oct & $(0,0,0)$ & 3000 & -623.04 & 1250.09 & 1255.6 & 1250.2 \\
Nov & $(0,0,0)$ & 90.95 & -422.02 & 848.04 & 853.53 & 848.15 \\
Dec & $(0,0,0)$ & 35.66 & -368.17 & 740.35 & 745.84 & 740.46 \\
Pre Monsoon & $(0,0,0)$ & 2356 & -609.16 & 1222.31 & 1227.8 & 1222.42 \\
SW Monsoon & $(0,0,0)$ & 36376 & -766.52 & 1537.04 & 1542.5 & 1537.15 \\
Post Monsoon & $(0,0,0)$ & 2995 & -622.94 & 1249.89 & 1255.4 & 1249.99 \\
Annual & $(0,0,0)$ & 46676 & -780.86 & 1565.71 & 1571.2 & 1565.82 \\
\hline
\end{tabular}

Table 5: Forecasting for monthly, seasonal and annual rainfall and average annual maximum and minimum temperature

\begin{tabular}{lllllllll}
\hline \multicolumn{2}{l}{ Rainfall prediction } & & & & & & \multicolumn{2}{c}{ Temp prediction } \\
Forecast & Feb & May & July & August & Winter & Forecast & Maximum & Minimum \\
2016 & 30.26 & 62.65 & 362.17 & 328.93 & 51.96 & 2016 & 29.30 & 19.85 \\
2017 & 20.16 & 62.65 & 331.93 & 328.93 & 49.90 & 2017 & 29.33 & 19.87 \\
2018 & 19.13 & 62.65 & 326.97 & 328.93 & 50.28 & 2018 & 29.38 & 19.87 \\
2019 & 19.72 & 62.65 & 326.16 & 328.93 & 50.21 & 2019 & 29.42 & 19.87 \\
2020 & 23.26 & 62.65 & 326.02 & 328.93 & 50.22 & 2020 & 29.44 & 19.87 \\
\hline
\end{tabular}

Table 6: Forecasting for monthly, seasonal and annual rainfall and average annual maximum and minimum temperature

\begin{tabular}{lllllllllllll}
\hline \multicolumn{2}{l}{ Rainfall predication } & & & & & & & & & & & \\
Forecast & Jan & Mar & Apr & Jun & Sep & Oct & Nov & Dec & Pre Monsoon & SW Monsoon & Post Monsoon & Annual \\
2016 & 16.84 & 24.10 & 22.27 & 190.63 & 212.01 & 3.70 & 7.44 & 3.70 & 87.25 & 1090.21 & 85.03 & 1312.80 \\
2017 & 16.84 & 24.10 & 22.27 & 190.63 & 212.01 & 3.70 & 7.44 & 3.70 & 87.25 & 1090.21 & 85.03 & 1312.80 \\
2018 & 16.84 & 24.10 & 22.27 & 190.63 & 212.01 & 3.70 & 7.44 & 3.70 & 87.25 & 1090.21 & 85.03 & 1312.80 \\
2019 & 16.84 & 24.10 & 22.27 & 190.63 & 212.01 & 3.70 & 7.44 & 3.70 & 87.25 & 1090.21 & 85.03 & 1312.80 \\
2020 & 16.84 & 24.10 & 22.27 & 190.63 & 212.01 & 3.70 & 7.44 & 3.70 & 87.25 & 1090.21 & 85.03 & 1312.80 \\
\hline
\end{tabular}

The forecasting of monthly, seasonal and annual rainfall and maximum and minimum temperature are presented in Table 5 and Table 6 . The forecast values suggest that the average rainfall for month Feb, May, July, August and winter season and maximum and minimum temperature are estimated different values for next five years forecasting and for month
Jan, Mar, Apr, June, Sept, Oct, Nov, Dec, Pre monsoon, SW monsoon, post monsoon season and annual average rainfall having same next five forecasting value. The forecasted average annual rainfall of the district for the period 2016 to 2020 is $1312.80 \mathrm{~mm}$ which is more than the national average annual rainfall, alone SW monsoon is contributed $1090.21 \mathrm{~mm}$ (i.e. 
approx. $80 \%$ of total avg. annual rainfall of the district) and post monsoon and pre monsoon is $85.03 \mathrm{~mm}$ and $87.25 \mathrm{~mm}$ respectively. Pre monsoon and post monsoon rainfall and temperature would help in preliminary agriculture cultivation planning. This would also be helpful in the planning and management of water resource and economic growth of the district.

\section{CONCLUSIONS}

An understanding of trends and forecasting of climatic variables (i.e., rainfall and temperature) would provide useful information for the planning, development and management of water and climate change in any area or region. The present study analyzed the climatic variable rainfall and temperature data for 115 years from 1901 to 2015 data for Ranchi district of Jharkhand state for the determination of the trend of monthly, seasonal and annual rainfall and maximum and minimum temperature and prediction and forecasting of next five year of rainfall and temperature time series. The analysis of data revealed that the significant decrease in the month of February and August average rainfall while increase in the month May and Pre-monsoon season over the Ranchi district. Except month February, May, August and Pre-monsoon season shows insignificant increasing as well as decreasing rainfall trend. The average annual maximum temperature and minimum temperature also shows decreasing and increasing trend over Ranchi district. Increasing trend in pre mon-

\section{REFERENCES}

Abeysingha NS, Singh M, Sehgal VK, Khanna M and Pathak H. 2014. Analysis of Rainfall and Temperature Trends in Gomti River Basin. Journal of Agricultural Physics 14(1):56-66.

Bera S. 2017. Trend Analysis of Rainfall in Ganga Basin, India during 1901-2000. American Journal of Climate Change 06(01):116-131. url: https://dx.doi.org/10.4236/ajcc.2017.61007. doi: 10.4236/ ajcc.2017.61007

Duhan D and Pandey A. 2013. Statistical analysis of long term spatial and temporal trends of precipitation during 1901-2002 at Madhya Pradesh, India. Atmospheric Research 122:136-149. url: https://dx.doi.org/10.1016/j.atmosres.2012.10.010. doi: 10. 1016/j.atmosres.2012.10.010

IPCC 2007. Contribution of Working Groups I, II and III to the Fourth Assessment Report of the Intergovernmental Panel on Climate Change. In Synthesis Report, volume 104.

Jain SK, Kumar V and Saharia M. 2013. Analysis of rainfall and temperature trends in northeast India. International Journal of Climatology 33(4):968-978. url: https://dx.doi.org/10.1002/joc. 3483. doi: 10.1002/joc.3483

Jeet P, Singh DK, Sarangi A, Singh SD and Kumar R. 2017. Modeling, probability analysis and forecasting of rainfall in Betwa river basin in Bundelkhand region. India. International Journal of Agriculture Innovations and Research 6(2):312-321.

Kumar M and Anand M. 2014. An application of time series ARIMA forecasting model for predicting sugarcane production in India. Studies in Business and Economics 9(1):81-94. soon and post monsoon would be help in management of water during the deficit SW monsoon seasons and significant increasing or decreasing temperature would help in forecasting of rainfall and cropping system. The average rainfall for month Feb, May, July, August and winter season fitted for $\operatorname{ARIMA}(3,1,3), \operatorname{ARIMA}(0,11), \operatorname{ARIMA}(1,0,0), \operatorname{ARIMA}(0,1,1)$ and $\operatorname{ARIMA}(1,0,0)$ respectively and these are able to forecast future times series of rainfall and temperature based on preceding time series data while annual as well as monthly and seasonal rainfall time series are fitted with $\operatorname{ARIMA}(0,0,0)$ are able to forecast future rainfall based on average value of previous time series data. The average annual rainfall of the district for the next five is estimated to be $1312.80 \mathrm{~mm}$, alone SW monsoon is contributed $1090.21 \mathrm{~mm}$ (i.e. approx. $80 \%$ of total avg. annual rainfall of the district) and post monsoon and pre monsoon is $85.03 \mathrm{~mm}$ and $87.25 \mathrm{~mm}$ respectively. Analyses of the rainfall and temperature data should be useful for irrigation and agricultural managers and can play an important role in managing water resources more effectively and sustainably in the Ranchi district.

\section{ACKNOWLEDGEMENTS}

The authors would like to express their deepest thanks to ICAR-IASRI, New Delhi for all their support during my Professional Attachment Training (PAT) and also to anonymous reviewer for helping in improving the quality of paper.

Kumar M, Denis DM and Suryavanshi S. 2016. Long-term climatic trend analysis of Giridih district, Jharkhand (India) using statistical approach. Modeling Earth Systems and Environment 2(3):1-10. url: https://dx.doi.org/10.1007/s40808-0160162-2. doi: 10.1007/s40808-016-0162-2

Kumari P, Ojha RK, Kumar WA and R. 2014. Rainfall and drought characteristics for crop planning in Palamau region of Jharkhand. Mausam 65(1):67-72.

Li X 2009. Applying GLM Model and ARIMA Model to the Analysis of Monthly Temperature of Stockholm. D-level Essay in Statistics. Department of Economics and Society. Dalarna University. Sweden. .

Ma T and Malini BH. 2003. Climatic variability in Jharkhand State. India. Deccan Geographer 41(2):13-19.

Mali S, Das B, Choudhary J, Singh A and Bhatt B. 2017. Spatial and Temporal Trends of Monthly, Seasonal and Annual Precipitation in Districts of Jharkhand in India. British Journal of Applied Science E Technology 20(6):1-17. url: https://dx.doi.org/10.9734/ bjast/2017/33502. doi: 10.9734/bjast/2017/33502

Pohlert T 2016. Non-parametric trend tests and change-point detection. CC BY-ND, 4.

Sultana N and Hasan MM. 2015. Forecasting Temperature in the Coastal Area of Bay of Bengal-An Application of Box-Jenkins Seasonal ARIMA Model. Statistics 7(8).

Zhang X, Vincent LA, Wd H and Niitsoo A. 2000. Temperature and Rainfall Trends in Canada during the 20th Century. Atmosphere-Ocean 38(3):395-429. 


\section{Citation:}

Jeet P, Singh KN, Ranjan Kumar R, Gurung B, Singh AK and Upadhyaya A. 2021. Modeling and Trend Analysis of Climatic Variables of Ranchi District, Jharkhand. Journal of AgriSearch 8(2): 120-128 